\section{Conclusion}

Paediatric neurosurgery is a well established specialty in which significant recent advances have contributed greatly to patient care. An integrated multidisciplinary approach is essential for the management of most conditions. There remain many difficult challenges, but promising new treatment methods and techniques are continually being evaluated.

University of Cambridge Department of Neurosurgery,

ERIC P GUAZZO

East Anglia Regional Neurosurgery Unit,

Addenbrooke's Hospital,

Cambridge CB2 $2 Q Q$

1 Nulsen FE, Berker DP. Control of hydrocephalus by valve regulated shunt. 7 Neurosurg 1967; 26: 362-74.

Scott MR. Hydrocephalus. Vol 3: concepts in neurosurgery. Baltimore: Williams and Wilkins, 1990

3 Choux M, Genitoni L, Lang D, Gabriel L. Shunt implantation: reducing the incidence of shunt infection. $\mathcal{F}$ Neurosurg 1992; 77: 875-80.

4 Burke JF. The effective period of preventive antibiotic action in experimenta incisions and dermal lesions. Surgery $1961 ; 50: 161-8$.

5 Walters BC, Hoffman HJ, Hendrick EB, et al. Cerebrospinal fluid shun infection: influences on initial management and subsequent outcome. f Neurosurg 1984; 60: 1014-21.

6 Bircheit F, Martret D, Healy JL, et al. How to choose the best valve. Monogr Neural Sci 1982; 8: 184-7.
7 Sainte-Rose C, Hooven MD, Hirsch J-F. A new approach in the treatment of hydrocephalus. $\mathcal{F}$ Neurosurg 1987; 66: 213-26.

8 Czosnyka M, Batorski L, Roszkowski M, et al. Cerebrospinal compensation in hydrocephalic children. Childs Nerv Syst 1993; 9: 17-22.

9 Davis L. Neurological surgery. Philadelphia: Lea and Febiger, 1939: 405.

10 Jones RFC, Stening WA, Brydon M. Endoscopic third ventriculostomy. Neurosurgery 1990; 26: 86-92.

11 Auer LM, Holzer P, Ascher PW, Hepprer F. Endoscopic neurosurgery. Acta Neurochir (Wien) 1988; 90: 1-14.

12 Mainwaring KH, Rikate H, Kaplan A. Hydrocephalus management by endoscopy. Ann Neurol 1989; 26: 488.

13 Teasdale G, Murray G, Anderson A, et al. Risks of acute traumatic intracranial haematoma in children and adults: implications for managing head injuries. BMF 1990; 300: 363-7.

14 Pickard JD, Czosnyka M. Management of raised intracranial pressure. $f$ Neurol Neurosurg Psychiatry 1993 (in press).

15 Hall E, Braughler M, McCall JM. Antioxidant effects in brain and spinal cord injury. F Neurotrauma 1992; 9: 5165-70.

16 Parker R, Sutton L, Atkins T, et al. A prospective study of cognitive function in children receiving whole brain radiotherapy and chemotherapy: 2 year results. I Neurosurg 1989; 70: 707-13.

17 Cohen ME, Duffner PK. Brain tumours in children. Neurol Clin 1991; 9 (2), May.

18 Drake JM, Joy M, Goldenberg A, Kreindler D. Computer and robot-assisted resection of thalamic astrocytomas in children. Neurosurgery 1991; 29: 27-33. 19 Steiner L. Radiosurgery: baseline and trends. New York: Raven Press, 1992.

20 Barrow DL. Intracranial vascular malformation. Neurosurgical topics. Park Ridge, Illinois: American Association of Neurological Surgeons, 1990.

21 Mayer F, March W, Laws E, Sharbrough F. Temporal lobectomy in children with epilepsy. $\mathcal{F}$ Neurosurg 1986; 64: 371-6.

22 Sakamoto H, Hakura A, Fujitani K, Nishimura S. Surgical treatment of retethered spinal cord after repair of lipomyelomeningocoele. $\mathcal{F}$ Neurosurg 1991; 74: 709-14.

\title{
Body composition assessment
}

There is increasing recognition and awareness of the inability of classical measures of growth and development to meet the requirements of modern clinical medicine and biological research. Measurements such as weight and length provide useful but incomplete data relating to the growth or nutritional status of a child. Thus, more detailed assessment of body composition is being sought by those interested in paediatrics, nutrition, growth, and development.

There are numerous techniques that are used to assess body composition, the majority of which use a two compartment model: that is to divide the body into fat and fat free masses. Nevertheless, many such techniques are not easily applied in children because of either practical or ethical considerations. For example, underwater weighing to assess body density and hence body fat mass is clearly not applicable to young children. However, there are numerous approaches that can be used to assess body composition in the paediatric population each with their own advantages and disadvantages. The range of the technology utilised and the complexity of the various techniques is wide. Some of these techniques are described below.

\section{Anthropometry}

Estimates of body composition based upon simple straightforward anthropometric measurements have been available for many years. ${ }^{1-3}$ The majority of these methods rely on the ability of measurements of subcutaneous fat folds or skinfolds at selected sites to predict accurately total body fatness. It has never been thought that this approach was perfect and there are many problems associated with the model that are not easy to overcome. ${ }^{45}$ It has been shown that it is not possible in infants to predict total body fatness from the measurement of skinfold thicknesses to an appropriate level of accuracy, ${ }^{6}$ and the equations derived for use in childhood and adolescents are often extremely population specific.?

\section{Bioelectrical impedance}

This technique has become extremely popular in recent years. It is based upon the fact that the electrical resistance to a flow of current of $50 \mathrm{kHz}$ in the human body is related to the amount of total body water and hence fat free mass. As the technique is non-invasive, simple, precise, and relatively cheap it would seem to be an ideal body composition tool for use in paediatrics. There have been a number of validations of the technique ${ }^{8-10}$ and in contrast with anthropometric methods bioelectrical impedance seems to be much less population specific. However, problems have been reported with its use in the neonatal period but these may be associated - more with the difficulty of validation in this population rather than the model itself. As the technique theoretically predicts total body water ${ }^{11}$ care should be taken in assuming that the same degree of precision can be applied to derived estimates of fat free mass. The conversion of body water to measures of fat free mass assumes a constant level of hydration in lean tissue. Even so the correlation between bioelectrical impedance and estimates of body cell mass via the measurement of total body potassium has been shown to be high. ${ }^{12}$ Current research in this area indicates that a dual frequency or multifrequency current might enable both intracellular and extracellular water to be measured. ${ }^{13}$ Users of bioelectrical impedance apparatus should, however, ensure that the equations built into any associated software supplied with the equipment are appropriate for children.

\section{Assessment of total body water}

It is of course possible to measure total body water rather than use prediction equations. The most straightforward approach is to use an isotope of either hydrogen or oxygen in the form of water and apply a standard dilution principle. ${ }^{14}$ Tritiated water $\left({ }^{3} \mathrm{H}_{2} \mathrm{O}\right)$ is not normally used in children because of the radioactive nature of the isotope but deuter- 
ated water $\left({ }^{2} \mathrm{H}_{2} \mathrm{O}\right)$ and $\mathrm{H}_{2}{ }^{18} \mathrm{O}$ can be used. The latter isotope is extremely expensive and thus the use of deuterated water is the most common method of assessing total body water via stable isotopes. The major drawback in the use of this isotope is that there is exchange of the isotope with non-aqueous hydrogen in the body. This exchange is probably variable and possibly population specific. ${ }^{15}$ However, an assumption that the measured deuterium dilution space is $3 \%$ greater than true body water is a reasonable adjustment.

\section{Dual energy $x$ ray absorptiometry}

A potentially exciting advance in the assessment of body composition is the use of dual energy $x$ ray absorptiometry otherwise known as DEXA or more recently DXA. ${ }^{16}$ This technique consists of the use of two $x$ ray beams of differing energies (usually 40 and $80 \mathrm{keV}$ ). The $x$ rays are attenuated to different degrees as they pass through the body dependent upon the quantity and nature of the tissue. It is therefore possible to not only assess the quantity of the fat and fat free masses but also measure bone mineral content. Moreover, segmental body composition analysis can be undertaken with this system. The radiation dose incurred is sufficiently small to be ethically acceptable for use in children. Dual energy $x$ ray absorptiometry has now been extensively used in adults although little work has been carried out in children. There are some concerns that the differences in the size, shape, and body geometry of children may require important changes to be made in the calibration procedures and in the mathematical computations involved in the technique. ${ }^{17} \mathrm{DXA}$ is never likely to be a widespread 'bedside' technique but should enable less expensive and more accessible techniques to be validated with greater ease and accuracy.

The future for body composition research in the paediatric population will undoubtedly involve a move away from the traditional two compartment models described. It is likely that greater accuracy and precision will be obtained using three or even four compartment models. The techniques described above may then be used together to derive estimates of fat mass, body water, mineral content, and protein content. It has been shown that three and four compartment models have at least theoretical advantages over a two compartment model in that variations in the relationship between components such as mineral, nonmineral, and water are associated with smaller errors in the final estimate of body composition. ${ }^{18}$ Such advances will be welcome by all working in the field.

\section{PETER S W DAVIES}

Infant and Child Nutrition Group,

Dunn Nutrition Unit,

Downhams Lane,

Milton Road,

Cambridge CB4 $1 X \mathcal{F}$

1 Parizkova J. Total body fat and skinfold thickness in children. Metabolism 1961; 10: 794-807.

2 Brook CGD. Determination of body composition of children from skinfold measurements. Arch Dis Child 1971; 46: 182-4.

3 Durnin JVGA, Rahaman MM. The assessment of the amount of fat in the human body from measurements of skinfold thickness. Br f Nutr 1967; 21: 681-9.

4 Martin AD, Ross WD, Drinkwater DT, Clarys JP. Prediction of body density by skinfold calipers: assumptions and cadaver evidence. Int $\mathcal{F}$ Obes 1985; 9: 31-9.

5 Brozek J, Kinzey W. Age changes in skinfold compressibility. F Gerontol 1960; 15: 44-51.

6 Davies PSW, Lucas A. The prediction of body fatness in early infancy. Early Hum Dev 1989; 21: 193-8.

7 Frerichs RR, Horsha DW, Berenson GS. Equations for estimating percentage body fat in children 10-14 years old. Pediatr Res 1979; 13: 170-4.

8 Davies PSW, Hicks CJ, Halliday D, Preece MA. The prediction of total body water using bioelectrical impedance in children and adolescents. Ann Hum water using bioelectrical

9 Cordain L, Whicker RE, Johnson JE. Body composition determination in children using bioelectrical impedance. Growth Dev Aging 1988; 52: 37-40.

10 Gregory JW, Greene SA, Scrimgeour CM, Rennie MJ. Body water measurements in growth disorders: a comparison of bioelectrical impedance and skinfold thickness techniques with isotope dilution. Arch-Dis Child 1991; 66: 220-2.

11 Hoffer EC, Meador CK, Simpson DC. Correlation of whole-body impedance with total body water volume. 7 Appl Physiol $1969 ; 27: 531-4$.

12 Houtkooper LB, Lohman TG, Going SB, Hall MC. Validity of bioelectrical impedance for body composition assessment in children. $\mathcal{F}$ Appl Physiol 1989; 66: 814-21.

13 Van Loan MD, Mayclin PL. Use of multi-frequency bioelectrical impedance analysis for the estimation of extracellular fluid. Eur $\mathcal{F}$ Clin Nutr 1992; 46: $117-24$.

14 Halliday D, Miller AG. Precise measurement of total body water using trace quantities of deuterium oxide. Biomedical Mass Spectrometry 1977; 4: 82-9.

15 Coward WA, Cole TJ. The doubly labelled water method for the measurement of energy expenditure in humans: risks and benefits. In: Whitehead RG, Prentice A, eds. New techniques in nutritional research. London: Academic Press, 1991.

16 Van Loan MD, Mayclin PL. Body composition assessment: duel-energy X-ray absorptiometry (DEXA) compared to reference methods. Eur 7 Clin Nutr 1992; 46: $125-30$.

17 Jebb SA, Goldberg GR, Elia M. DEXA measurements of fat in relation to depth and adiposity. Clinical Nutrition 1992; 11: 145

18 Elia M. Body composition analysis: an evaluation of 2 component models, multi-component models and beside techniques. Clinical Nutrition 1992; 11: $114-28$. 